\title{
Conflitos na gestão social do território: uma análise a partir da organização dos ilhéus em Porto Alegre
}

\author{
MÁRCIO ANDrÉ LEAL BAUER \\ Universidade Federal do RIO GRANDE / INSTITUTO de CIÊNCIAS ECONÔMICAS AdMINISTRATIVAS E CONTÁBEIS, \\ Programa de Pós-Graduação em Administração, Rio Grande - RS, Brasıl
}

\author{
ROSINHA da Silva Machado CaRrion \\ Universidade Federal do Rio Grande do Sul / Programa de Pós-Graduação em Administração, Porto Alegre - RS, Brasil
}

\begin{abstract}
Resumo
Este trabalho analisa a relação entre os conflitos e o surgimento de uma organização social que busca dar conta dos processos de gestão social do território. Parte-se da discussão a respeito da gestão social, como possibilidade de uma gestão pública, não estatal, que ocorre na esfera pública. A análise inclui a dimensão do conflito e a capacidade dos sujeitos de transcender os espaços formais em direção a esforços organizados para a gestão social do território. O estudo nas ilhas de Porto Alegre-RS revela o exercício da gestão social por parte de uma organização própria da comunidade que nasce em meio a uma série de conflitos e, por que não dizer, em razão deles. Tal gestão diz respeito às ações desenvolvidas pela comunidade para alcançar diversos fins (redistribuição, reconhecimento, respeito e autonomia) e que não se restringem à participação em espaços formais, como conselhos e instâncias de representação; muito menos é a articulação de atores formalmente constituídos ou movimentos sociais institucionalizados. Ela vai além para incluir os recursos informais, como as manifestações, os protestos, as ações simbólicas, os contatos políticos. Com efeito, não se limita à participação concedida, mas representa, também, aquela conquistada e que supera a fragmentação dos espaços públicos formais para representar algo em movimento, porém, estabelecido sobre a base de um território. É, portanto, uma "gestão social do território" feita nos espaços, entre eles e por meio deles.
\end{abstract}

Palavras-chave: Gestão Social. Conflito. Esfera Pública. Organização Social. Território.

\section{Conflicts in social management of the territory: an analysis through the organization of islets in Porto Alegre}

\begin{abstract}
This paper analyzes the relationship between conflicts and the emergence of a social organization that seeks to tackle social management procedures in the territory. It starts from the discussion on social management, as the possibility of a public management, not belonging to the State, which takes place in the public sphere. The analysis includes the dimension of conflict and the ability of individuals to go beyond the formal spaces towards organized efforts for social management of the territory. The study conducted in the islands of Porto Alegre, Rio Grande do Sul, Brazil, reveals the practice of social management through an organization inherent to the community that is born amid a series of conflicts and, why not saying it, because of them. The social management concerns actions taken by the community to achieve various purposes (redistribution, recognition, respect, and autonomy) and they are not restricted to participation in formal spaces, such as councils and representation bodies; also, it is not the interconnection between formally constituted actors or institutionalized social movements. It goes further to include informal resources, such as manifestations, outcries, symbolic actions, political contacts. Indeed, it is not limited to the participation granted, but also represents the conquered one that overcomes the fragmentation of formal public spaces to represent something in motion, but established on the basis of a territory. It is, therefore, a "social management of the territory" taking place in the spaces, between them, and through them.
\end{abstract}

Keywords: Social Management. Conflict. Public Sphere. Social Organization. Territory.

\section{Conflictos en la gestión social del territorio: un análisis de la organización de los isleños en Porto Alegre}

\section{Resumen}

En este trabajo se analiza la relación entre el conflicto y la emergencia de una organización social que busca sostener los procesos de gestión social del territorio. Se inicia con la discusión de la gestión social, como posibilidad de realización de una gestión pública, no estatal, que se produce en la esfera pública. El análisis incluye la dimensión del conflicto y de la capacidad de las personas para trascender los espacios formales en dirección a esfuerzos organizados para la gestión social del territorio. El estudio sobre las islas de Porto Alegre-RS revela el ejercicio de la gestión social por una organización de la comunidad que nace en medio de una serie de conflictos y, por qué no decirlo, del efecto de ellos. Esta gestión se refiere a las acciones desarrolladas por la Comunidad con diferentes propósitos (redistribución, reconocimiento, el respeto y la autonomía) y no se limita a la participación en espacios formales como consejos y espacios representativos; mucho menos es la articulación de actores formalmente constituidos o movimientos sociales institucionalizados. Se extiende para incluir las acciones informales, tales como manifestaciones, protestas, acciones simbólicas, contactos políticos. Esta gestión no se limita a la participación concedida, pero es también la que se logra. Supera la fragmentación de los espacios públicos formales para representar algo en movimiento, sin embargo establecido sobre la base de un territorio. Es por lo tanto una "gestión social del territorio" hecho en los espacios, entre ellos y a través de ellos.

Palabras clave: Gestión Social. Conflicto. Esfera Pública. Organización Social. Territorio. 


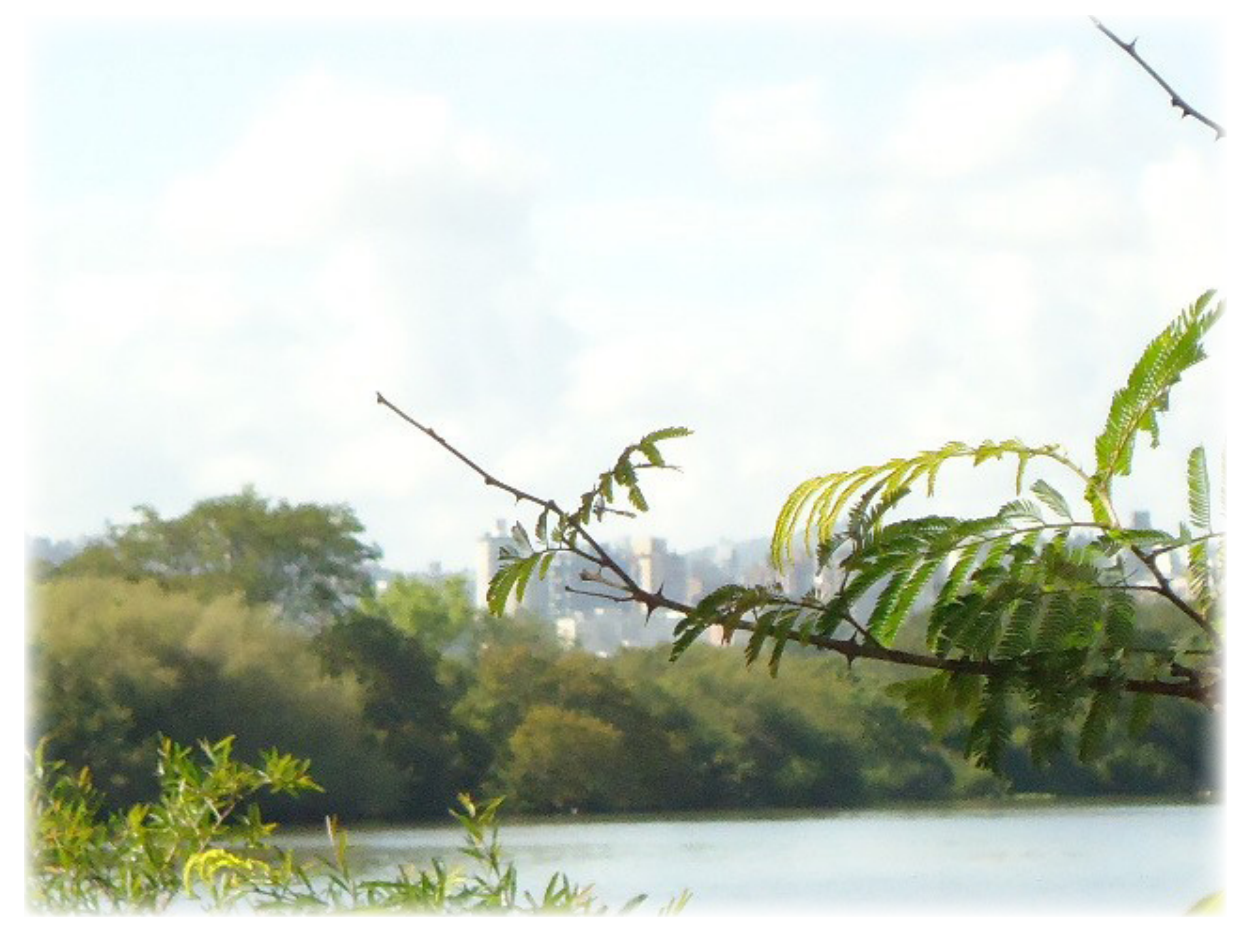

\section{INTRODUÇÃO}

Não é de hoje que se discute o tema da participação social na gestão pública e, da mesma forma, a maneira como a sociedade civil organiza-se para exercer essa participação. Inicialmente, buscava-se compreender o papel da participação em meio à transição de um regime autoritário para uma democracia. A novidade daqueles movimentos estava ligada tanto ao processo de recriação de espaços públicos a partir do cotidiano, quanto à diversidade das manifestações de luta e formas de organização de base que ocorriam "por fora" da institucionalidade, exigindo, do Estado, participação direta nas decisões (SILVA, 2003). O crescimento das formas de organização da sociedade civil é considerado um dos elementos mais importantes da democratização do país. $\mathrm{O}$ auge desse movimento foi o processo constituinte que propôs as chamadas "emendas populares", abrindo espaço para práticas participativas nas áreas de políticas públicas que culminaram na promulgação da Constituição de 1988 (AVRITZER, 2009).

Entretanto, se a Constituição tem sido considerada em muitas narrativas a origem da participação social na gestão pública, não se pode esquecer que ela é resultante de conflitos entre organizações com distintas concepções acerca do projeto democrático. À medida que se institucionalizava os novos mecanismos constitucionais de cogestão e generalizava-se experiências locais de participação, como o orçamento participativo (OP), foi possível constatar que a simples existência do espaço formal deliberativo, criado muitas vezes por exigência legal para o repasse de recursos federais, não garantia a participação nem a qualidade do processo deliberativo. Diante das políticas neoliberais dos anos 1990, os espaços acabavam, por vezes, servindo mais à legitimação das decisões governamentais que ao empoderamento da sociedade civil no controle e direcionamento do Estado (KAUCHAKJE, 2008).

Por conta disso, surgiram muitas críticas afirmando que as práticas participativas nos espaços públicos teriam intenções autolegitimadoras, uma vez que estes, por ser instituídos pelo Estado, serviriam como instrumentos de cooptação (CUNHA, 1993;

* Fonte da imagem: Pavão visto da ilha grande / Márcio Bauer (arquivo pessoal da pesquisa de campo). 
DAGNINO, 1994), em que a dimensão política da ação coletiva estaria ou desaparecendo ou sendo capturada pelas estruturas políticas, "de cima para baixo, na busca de coesão e controle do social" (GOHN, 2008, p. 14). Em parte, tais críticas devem-se às grandes expectativas geradas com a criação desses espaços, especialmente em relação à atuação dos movimentos sociais como protagonistas em sua dinamização (AVRITZER, 1999). Em suma, o argumento que unia a participação aos movimentos e organizações sociais parece ter perdido a força diante dos riscos de despolitização no contexto da chamada "democracia gerencial" (TATAGIBA, 2006). Paradoxalmente, é essa aproximação entre democracia e gestão que constituirá o eixo de análise da gestão social (GS), como possibilidade de uma gestão pública, não estatal, em um "processo dialético" que combina administração e política (PAULA, 2005, p. 47).

Do ponto de vista ideal-típico, a GS representa "a tomada de decisão coletiva, sem coerção, baseada na inteligibilidade da linguagem, na dialogicidade e no entendimento esclarecido como processo, na transparência como pressuposto e na emancipação como fim último" (CANÇADO, TENÓRIO e PEREIRA, 2011, p. 1). Contudo, se a gestão social não é apenas um conceito normativo, mas um campo de estudos que abrange a participação social na esfera pública (OLIVEIRA, CANÇADO e PEREIRA, 2010), a compreensão de seus avanços e limitações implica sua inscrição em um debate mais amplo nas ciências sociais (AVRITZER, 1999; 2008; 2009; DAGNINO, 1994; DAGNINO, OLIVEIRA e PANFICHI, 2006; DAGNINO e TATAGIBA, 2007; GOHN, 2011), em que o conceito habermasiano de esfera pública² é considerado central (AVRITZER e COSTA, 2004; LORD, 2007; OLIVEIRA, CANÇADO e PEREIRA, 2010).

No entanto, dado o grau de abstração desse conceito, sua apropriação pela realidade empírica tem sido problemática, gerando um afastamento do conceito original, em direção à análise dos espaços públicos concretos, como conselhos, fóruns e outros espaços de discussão e deliberação (LORD, 2007). Tais análises têm identificado uma série de "problemas", tais como: a predominância dos gestores no processo; a minimização do conflito e pouco debate (PERISSINOTTO e FUKS, 2007); a falta de capacitação técnica e política dos conselheiros; a representação em bases pessoais vinculada a interesses privados (SILVA et al., 2009), reforçada por um modelo que estimula a participação individual dos cidadãos, "sem que estejam, necessariamente, organizados em grupos ou representando associações" (MILANI, 2008, p. 565-566). Tais críticas, embora pertinentes, têm o viés da análise da participação no interior dos "espaços físicos", os quais, para Habermas servem como base inicial para a publicização de temas, mas não são capazes de representar os fluxos comunicativos da esfera pública nem traduzir os seus critérios de legitimidade (LORD, 2007, p. 459).

Por outro lado, a própria noção habermasiana de uma esfera pública "autônoma", oriunda da racionalidade comunicativa, é igualmente problemática, pois desconsidera a importância do conflito (HONNETH, 1991; NOBRE, 2003)3 e deixa em aberto um ponto fundamental à sua instrumentalização: "quais condições garantem a uma interação comunicativa simples ter potencial para gerar, ao final do processo, a esfera pública?". Faltaria a ela um estágio anterior à própria ação comunicativa, que diz respeito às interações simples entre sujeitos (LORD, 2007, p. 463) em sua realidade cotidiana.

Os argumentos acima esboçados não implicam abandono da noção de esfera pública, mas ampliação de seu entendimento para que se possa reconhecer que a gestão social se desenrola também em esferas marcadas por relações de conflito e disputa, nas quais a manipulação e a exclusão também ocorrem e onde não somente podem ser produzidos consensos, mas também dissensos e falsos consensos em que uma hegemonia pode ser produzida (PEREIRA, 2007; MILANI, 2008). Contudo, nos parece que o lócus de análise deve transcender os espaços concretos de decisão, em direção às relações sociais que se estabelecem em um determinado território (MESQUITA, 1995; ORTIZ, 1999; MESQUITA e BAUER, 2008; SOLINÍS, 2009) e configuram processos organizacionais.

Este trabalho analisa a complexa relação entre os conflitos vivenciados pelos moradores das ilhas de Porto Alegre e o surgimento de uma organização social que busca dar conta dos processos de gestão social do território. Ao trazer para a análise essa realidade sui generis da capital gaúcha - conhecida por suas inovações no que diz respeito à participação na gestão pública - espera-se

\footnotetext{
${ }^{2}$ A esfera pública representa, para Habermas, um fenômeno social que não deve ser confundido com uma organização, instituição ou sistema, podendo melhor ser descrita como uma rede "para comunicação de conteúdos, tomadas de posição e opiniões" que "se reproduz a partir do agir comunicativo", ou seja, através de interpretações "negociadas cooperativamente" em um espaço (arena, palco, fórum), seja ele real ou virtual, concreto ou abstrato (HABERMAS, 2011, p. 93)

${ }^{3}$ É bem verdade que Habermas (2011) não desconsidera a existência do conflito e de estruturas de poder e influência na esfera pública. No entanto, ele os considera como passíveis de identificação, tematização e possível neutralização por parte daqueles que, em seu interior, assumem a discussão pública. Estes podem criar, inclusive, mecanismos de exclusão, o que implica uma consciência dos mecanismos sistêmicos de dominação.
} 
contribuir para ampliar a compreensão do objeto da gestão social e sua respectiva forma de análise. $O$ artigo é estruturado na forma de um diálogo entre teoria e dados empíricos, sendo composto de cinco partes, além desta introdução. Na seção seguinte, são apresentados os procedimentos metodológicos realizados. A terceira seção narra a constituição do território das ilhas. A seguir, é feita uma descrição dos processos que levaram à formação da organização territorial dos ilhéus. Na quinta seção é apresentada uma análise dos resultados da pesquisa. A parte final do artigo expõe as conclusões e contribuições do estudo.

\section{ACERCA DO ESTUDO}

Este estudo é o resultado das observações realizadas de 2007 a 2013 no bairro Arquipélago, em Porto Alegre. O local é constituído por cerca de 30 ilhas, das quais são habitadas apenas 5: Pintada, Mauá, Flores, Pavão e llha Grande dos Marinheiros (IGM). No início da pesquisa, em 2007, sabia-se que a maioria dos levantamentos socioeconômicos apresentava "dados" desfavoráveis sobre a região. A análise multidimensional da pobreza em Porto Alegre (COMIN, BAGOLIN, AVILA et al., 2006) situava a região abaixo da média geral da cidade nas questões de saúde, nutrição, educação e conhecimento. Paradoxalmente, em três indicadores, de caráter qualitativo (participação, solidariedade e liberdade/satisfação), a região superava a média da cidade.

A primeira visita ocorreu três dias depois de uma grande manifestação, em outubro de 2007, que reuniu várias lideranças de organizações do Arquipélago em uma marcha rumo à prefeitura. Nas conversas foi possível identificar certo conflito entre as organizações locais e a prefeitura. "O pessoal ficou muito mais forte, todos se uniram para combater a prefeitura", dizia uma liderança. Percebeu-se, já de início, que essa dinâmica havia mobilizado as diferentes ilhas, a partir de um processo de organização da própria comunidade, sem a interferência de agentes externos.

Esse fato foi fundamental para a decisão de aprofundar os estudos na região, a fim de conhecer a história e organização social dos ilhéus.

Inicialmente foi feito um levantamento (pesquisas já realizadas no território, documentos produzidos pelos agentes externos, notícias de jornal, internet) que possibilitou compreender, além da história das ilhas e de seus habitantes, as orientações teóricas e metodológicas que sustentam as visões sobre o território. Paralelamente, realizou-se um trabalho de observação da dinâmica do território, a partir da presença semanal em reuniões, e espaços de participação no território por um período de dois anos. Com esse trabalho, foi possível identificar como ocorre a organização do território, as principais lideranças e suas respectivas práticas nas organizações e espaços, assim como as ações coletivas por elas engendradas.

A partir dessa identificação, realizou-se um conjunto de entrevistas com 19 lideranças locais, além de outros moradores e agentes envolvidos com o território (participantes de organizações não governamentais (ONG), do poder público, e de outras organizações). Além das entrevistas, foram objeto de registro as conversas informais com moradores antigos. $\mathrm{O}$ critério de escolha dos entrevistados foi o julgamento, a partir da observação realizada nas organizações e espaços do território. As entrevistas, na forma de depoimentos, foram abertas, ou seja, quem decidia o que iria relatar era o próprio entrevistado (QUEIROZ, 1988), elas foram feitas no próprio local de trabalho ou residência do entrevistado. A maioria dos depoimentos foi gravada e depois transcrita, para que nenhum elemento essencial fosse perdido (já que, diferente da análise de conteúdo, os temas ou as categorias foram identificados pela importância e centralidade e não pela frequência em que ocorreram).

Recorreu-se, também, à observação participante em eventos e reuniões de grupo, bem como em atividades cotidianas das lideranças dos ilhéus. Ela teve como objetivo captar os momentos de interação, os conflitos e relacioná-los com as narrativas dos depoimentos, dando-lhes pleno sentido. Vale dizer que nomes de pessoas e organizações foram alterados para preservar a identidade dos sujeitos da pesquisa.

\section{A CONSTITUIÇÃO DO TERRITÓRIO DAS ILHAS}

Neste estudo, optou-se pela referência ao termo "ilhas", em vez de bairro Arquipélago - denominação associada ao espaço imobiliário e de moradia de uma classe mais abastada - ou mesmo Delta do Jacuí, invocado por ambientalistas e acadêmicos em geral, visto que ambas remetem ao poder régio do Estado de instituir (BOURDIEU, 1989). Já a referência às "ilhas" 
é reivindicada pelos moradores locais como seu território, um espaço com significação individual e social, cujos limites não são físicos, mas determinados pela territorialidade, ou seja, a vivência do espaço físico e cultural como extensão dos sujeitos que ali vivem; e projeção de suas identidades como indivíduos ou grupo (MESQUITA, 1995).

Mesmo sendo o Arquipélago um dos bairros da cidade, a territorialidade dos ilhéus é construída em contraste com a de "Porto Alegre". Sua construção está ligada aos processos de territorialização, desterritorialização e reterritorialização (MESQUITA, 1995; ORTIZ, 1999; MESQUITA e BAUER, 2008) vividos por muitos de seus habitantes. Primeiro, muitas pessoas que hoje são lideranças, foram removidas de suas residências e "jogadas" nas ilhas sem qualquer recurso. Entretanto, por mais desestruturante que tenha sido tal processo de urbanização (SOLINÍS, 2009), essa desterritorialização (desenraizamento) acaba ensejando uma nova territorialidade forjada na luta comum de várias lideranças das ilhas e que só pode ser compreendida a partir de um olhar histórico sobre a constituição do território.

Apesar de as ilhas serem habitadas há séculos (índios, descendentes de escravos, açorianos, pescadores e agricultores), foi com a construção das pontes, em 1959, que a ocupação do território intensificou-se. As margens da rodovia foram aterradas e representavam um local relativamente protegido contra as cheias, comuns na região (GOMES, MACHADO e VENTIMINGLIA, 1995; PORTO ALEGRE, 2008). Entretanto, o aumento do número de moradores nas ilhas não é resultado apenas de um processo de ocupação "natural", ou mesmo "invasão" de moradores a terrenos públicos. Contribuiu para isso a ação direta do Estado, por meio de desocupações promovidas em razão de grandes obras de modernização e urbanização (a rodovia Porto Alegre-Osório e o Aeroporto Salgado Filho são alguns exemplos).

\section{Ai, eles chegaram e disseram: "Tu tens que ir embora daqui. Tu tens que sair e deu! Vocês moram embaixo de um sinalizador de avião e tu tens que sair". E eu disse: "Não, mas eu não vou sair". "Tu vais sair, sim. Tu tens dez minutos para arrumar as tuas coisas" [...]. Daí, só deram tempo pra gente entrouxar o que tinha, jogaram para cima do caminhão e fizeram a pergunta: "Pra onde tu quer ir? Tu tens duas opções: Ilha ou Restinga" (Violeta).}

Nesse processo foram desocupadas vilas inteiras do centro e dos arredores, e muitos moradores levados (ou jogados nas ilhas) ${ }^{4}$, como o caso das Vilas Dona Teodora, Areia e Tio Zeca. Quem não podia, ou não queria ir para a distante Restinga, tinha como alternativa as ilhas, que, mesmo sem água ou luz, representavam um local mais próximo de quem trabalhava no centro.

Esse mesmo estado criaria, em 1976, por um decreto do então governador Sinval Guazzelli, o Parque Estadual Delta do Jacuí (PEDJ), com objetivos meramente preservacionistas, as populações ali existentes eram vistas normalmente como vilãs e responsáveis pelo processo de degradação do ambiente natural ${ }^{5}$. Isso somado ao contexto político da época (em plena ditadura militar), resulta em um conjunto de decisões que foram tomadas sem a participação, ou mesmo sem que a população local fosse ouvida. Em nenhum momento houve a intenção de qualificar as habitações e a malha viária existente, na esperança de que os moradores acabassem deixando o local, o que não ocorreu (MOSCARELLI et al., 2005).

Diante das desterritorializações e situações de conflito com o Estado, os moradores das ilhas percorreram um longo caminho de organização e participação política para conquistar direitos básicos.

\footnotetext{
${ }^{4}$ Estava em curso nesse período, caracterizado pela violência de uma ditadura militar, o projeto "Remover para Promover" que se abatia sobre as populações urbanas faveladas, "jogando milhares de pessoas para periferias distantes e sem infraestrutura" (BAIERLE, 2007, p. 22). Conforme relato dos moradores mais antigos, as casas eram demolidas e as pessoas eram "jogadas" na ilha "de barraca e sem comida [...] passando fome, passando miséria. [...] Eu me apavorei quando vi as casas quebradas [em cima do caminhão da prefeitura]" (Moradora da llha Grande).

${ }^{5}$ É importante lembrar que a destruição do ambiente natural do delta do Jacuí teve a participação do poder público, como a Ilha da Coroa dos Bagres, inteiramente degradada pela retirada de areia para o aterro da Praia de Belas; e a llha do Pavão, utilizada como destino dos resíduos sólidos da capital no período entre 1973 e 1976 (BRANCO FILHO e BASSO, 2005). Atualmente, muitos debates em torno do lixo nas ilhas abordam apenas a questão da reciclagem e dos carroceiros, omitindo a poluição industrial que é despejada nos rios que deságuam no estuário do Guaíba, como também as dragas que retiram toneladas de areia diariamente.
} 


\section{A CONSTRUÇÃO DA ORGANIZAÇÃO TERRITORIAL DOS ILHÉUS}

Na Ilha Grande, a organização começa com uma irmã religiosa e um engenheiro que passaram a residir no local. Eles, com o apoio de dirigentes de uma organização espírita, fundam a Associação de Moradores da Ilha Grande. Com o objetivo de buscar melhorias para a ilha (especialmente água e luz), essa associação seria o primeiro espaço de participação e formação de lideranças locais como Margarida e, posteriormente, Violeta. Contudo, percebe-se, desde o início, que a luta não se restringia ao espaço formal da associação.

\section{Aí, a gente se revoltou [...] Aí, começou abaixo-assinado. Muitas vezes a gente trancava a ponte, a gente} fazia horrores. [...] A gente se reunia às vezes até debaixo de uma árvore (Violeta).

A partir da mobilização das lideranças (via abaixo-assinados, protestos e reuniões), algumas melhorias são conquistadas. Embora a associação formal tenha perdido seu foco nos anos 1980, sendo transformada em mera agremiação esportiva, esse processo participativo resultou em um importante aprendizado para o que viria anos mais tarde com a implantação do OP, daí, a interpretação de lideranças mais antigas de que "o OP nasceu nas Ilhas" (Margarida), dada a simbiose inicial entre organizações locais e partidos políticos de esquerda, como Partido dos Trabalhadores (PT) e Partido Democrático Trabalhista (PDT), que buscavam ali um apoio para sua criação e/ou consolidação de suas bases. Sob essa influência, foram fundadas associações de moradores em diversas ilhas. Todavia, o trabalho de desenvolvimento comunitário e participação política nas ilhas não se deve somente aos partidos. Em grande parte, foi o resultado da atuação de religiosos, como é o caso dos freis capuchinhos na Ilha da Pintada e os maristas na Ilha Grande e Ilha do Pavão.

Nessas ilhas, a organização dos moradores também ocorreu em torno da reciclagem, tendo em vista que eram usadas pelo poder público e iniciativa privada como local para depósito do lixo da capital. Entretanto, o lixo trouxe, também, um estigma para a comunidade, sobretudo após a divulgação do polêmico filme Ilha das Flores. Esse filme distorceu a verdadeira relação dos moradores com o lixo e com a criação de porcos, mostrando uma imagem bastante incômoda da Capital ${ }^{6}$. Ele foi o estopim para uma série de conflitos dos moradores com o poder público. O Ministério Público Estadual começou a pressionar a prefeitura e o governo do estado para a efetiva implantação do Parque Estadual Delta do Jacuí. Por conseguinte, os moradores passaram a sofrer ações de repressão à criação de porcos por parte da Polícia Rodoviária Federal e da Brigada Militar. Segundo relatos, esses conflitos geraram reações da comunidade que começou a organizar ações de protesto.

\section{E trancava a ponte. Ou senão se trazia todo o pessoal de caminhão e vinha pra prefeitura. Aí, o que o pessoal fazia? Se sujava com cocô do porco, que é um fedor desgraçado, e entravam pra dentro da Prefeitura. Num instantinho eles chamavam pra negociar (Violeta).}

Contudo, uma proposta concreta para solução do problema só foi efetivada em 1999, 10 anos depois do filme, quando o PT, que já governava a capital havia 10 anos, assume o governo do estado e cria o programa "Coletivos de Trabalho". A partir da proposta desse programa foi criada a Cooperativa da Ilha Grande, com o sonho de unir as diversas lideranças das ilhas em torno de um empreendimento econômico solidário. Maricá, morador da llha Grande, assumiu a presidência da cooperativa e firmou-se como liderança forte no Arquipélago. Sua gestão, no entanto, foi marcada por muitas controvérsias, levando inúmeras lideranças a deixar de participar por não se adaptar ao seu estilo de administração. A Cooperativa acabou tornando-se "uma rede fechada, restrita" (liderança da comunidade), perdendo sua referência como mobilizadora das ações coletivas, como a manifestação de 2007, narrada na seção anterior.

\footnotetext{
${ }^{6}$ Entretanto, o filme e os debates posteriores não colocaram em pauta o problema socioambiental gerado pela ocupação das margens dos rios por moradias de alto padrão. De acordo com moradores antigos, a "briga contra os porcos" começou quando "os ricos começaram a invadir o lado sul" (Margarida) da Ilha Grande. No discurso, essa "briga" seria uma briga contra o lixo, mas para os moradores tratava-se de uma briga contra os pobres. De fato, o problema central não eram os porcos, muito menos sua alimentação à base de lixo, pois a prefeitura, nesse mesmo período, criara um programa para alimentação de porcos com o lixo em outros locais da capital, por meio de uma parceria entre o Departamento Municipal de Limpeza Urbana (DMLU) e uma associação de criadores de suínos (cf. WAISMAN, 2002). O programa recebeu destaque mundial em publicação do Centro Internacional de Pesquisas para o Desenvolvimento (CRD), do Canadá, e outros parceiros, na qual se lê: "Em Porto Alegre (Brasil), 16 criadores de porcos agrupados na Associação de Porcicultores beneficiaram-se de um programa financiado com o Orçamento Participativo. A Prefeitura realizou a coleta dos RSO [resíduos], seu tratamento e transporte para um centro de distribuição e entregou a cada criador 6 kg de alimentos tratados para animais" (FLORES, 2003, p. 4).
} 
Outro movimento associativo importante nas ilhas do Pavão e Grande dos Marinheiros foi o dos carroceiros. Desde o início dos anos 2000, eles já lutavam contra a retirada de circulação das carroças em Porto Alegre. A Associação dos Carroceiros I, da qual Ingá era presidente, unia os carroceiros da Ilha Grande dos Marinheiros e entendia que a luta dos carroceiros não devia estar articulada com espaços formais de decisão como redes e fóruns, porque não tinha confiança nem no governo e muito menos nas ONG que ali estavam presentes. No entanto, tinha relações estreitas com o Movimento Nacional dos Catadores de Materiais Recicláveis (MNCR) e a Central Única dos Trabalhadores (CUT). Tal envolvimento gerou divergências internas que culminaram com a saída de Gravatá, outra liderança local dos carroceiros. Ele, incentivado pela Força Sindical, criou, em 2006, a Associação dos Carroceiros II.

A separação não gerou hostilidade entre as duas associações, mas acabou dividindo os carroceiros em um momento fundamental de sua luta quando da elaboração e posterior votação da "Lei das Carroças" (Lei Municipal n. 10.531/2008), que proibia a circulação de carroças em Porto Alegre. De um lado, a Associação de Carroceiros I, aliada do MNCR e da CUT, preocupava-se com as novas possibilidades no cenário político nacional, em que se vislumbravam oportunidades de recursos para os empreendimentos de reciclagem. De outro, a Carroceiros II, que buscava uma aproximação com a prefeitura para salvaguardar os interesses de seus associados. Apesar da recusa das lideranças dos carroceiros em se envolver com outras demandas importantes dos moradores e participar dos espaços deliberativos, eles receberam, em muitos momentos, apoio de outras lideranças das ilhas que, em sentido inverso, caminharam para a ocupação dos espaços públicos formais e ampliação da luta pelo direito de permanecer em seu território.

Para compreender a criação de espaços públicos deliberativos no território é preciso voltar a 1989, quando, depois do mandato de três anos de Alceu Collares, do PDT, na Prefeitura de Porto Alegre, o PT alcança o poder com a eleição de Olívio Dutra e implanta o OP. Com isso, as lideranças das diferentes ilhas começam a se encontrar em um mesmo espaço e percebem a necessidade de unir-se para lutar pelos interesses de seu território, uma vez que estavam atreladas a uma região mais abrangente, a região Humaitá/Navegantes. "Em 1998 era o debate deles se separar [...] Eles sempre debateram e defenderam essa possibilidade [...] Eu sempre ouvi isso e era uma coisa assim determinante pra eles" (Palmeira, ex-coordenadora do OP na região).

Em 1999, chega ao território uma psicóloga social contratada pela prefeitura, para trabalhar na llha Grande dos Marinheiros. Ela foi uma das principais responsáveis pela articulação da comunidade em torno do espaço da Rede Integrada de Proteção à Criança e Adolescente do Arquipélago (RIPCA). A partir da criação da RIPCA,

[...] foi vivenciado um crescimento comunitário [...] com maior integração entre as lideranças das ilhas. As reuniões da Rede passam a ser um espaço público comunitário com um forte caráter de organização da comunidade, promovendo debates e chamando os órgãos públicos para dentro das ilhas (Relato da psicóloga).

Na visão dos ilhéus, a integração entre as lideranças se deu em sentido um pouco diferente. Surge pela necessidade de resistir à possibilidade de desocupação da Ilha do Pavão, pois começaram a perceber que a pressão para sua saída do Arquipélago estava aumentando.

A gente começou a se organizar. Na época quem avisou nós foi [o vereador $\mathrm{X}$ ], que era pra tomar cuidado que eles iam atropelar o pessoal que morava ali. [...] Pegamos o pessoal da llha da Pintada, da Ilha das Flores e da llha dos Marinheiros e nos reunimos. Foi aí que começou as reuniões de rede [RIPCA] (Violeta - Ilha Grande dos Marinheiros).

Naquele momento, era necessário unir todas as ilhas em torno do direito de habitar no território, o que reforçou a união entre as lideranças das ilhas.

Por duas vezes a gente chamou e eles [moradores de outras ilhas] vieram pra cá. Quando eles [poder público] pensaram em vir pra cá despejar, isso aqui já tava tomado pelas pessoas. E quando foi pra nós pedir água pra todo mundo, todo mundo tava aqui. Foi aqui que começou tudo. [...]. Faz uns sete pra oito anos que começou tudo isso (Corticeira - Ilha do Pavão).

No entanto, a luta pela moradia não ocorreu somente no espaço formal da RIPCA. Um pequeno grupo de lideranças das diferentes ilhas começou a se reunir de forma sistemática para discutir as maneiras de manter os ilhéus no Arquipélago. A ideia 
central era "garantir a permanência dos ilhéus no seu território" (Rosa). Inicialmente, ainda no governo de Olívio Dutra, do PT, o grupo reuniu-se com o secretário do Meio Ambiente para tentar a "redefinição dos limites do parque" (Irmão Gerânio), auxiliando nos estudos para que as áreas onde houvesse moradores deixassem de ser parque e se tornassem uma Área de Preservação Ambiental (APA). Nos mais diversos espaços (audiências públicas, reuniões), quando o tema era a APA, lá estava a "equipe", ou o "grupo das ilhas", pressionando e exigindo mudanças na legislação que contemplassem os interesses dos moradores. Compunham essa organização social, que se formou para discutir o processo da APA, [...] a Rosa, o Junco, a Margarida, depois entrou a Violeta, bem no final, o Cravo (Palmeira).

Então, a nossa equipe... Nós sempre tivemos reunidos, provocando reuniões, encontros, com tudo que é autoridade e assim por diante, fazendo a coisa caminhar e acontecer, que então vinha se arrastando. $E$ depois de cinco anos conseguimos através de lei, porque decreto não resolvia (Irmão Gerânio - Ilha Grande).

Considerando que cada esfera decisória "tinha uma preocupação com as ilhas [...]. Aquelas lideranças preparadas acompanhavam esse processo. Elas traziam essas coisas todas pra nós que estavam soltas" (Palmeira). Tudo estava sendo construído com a participação dos ilhéus em audiências públicas, reuniões informais e comissões da Assembleia Legislativa. "Era lido item por item e debatido item por item. Tudo feito em grupo com as lideranças, ecologistas..." (Palmeira).

No entanto, a Secretaria Estadual do Meio Ambiente acabou elaborando outro projeto de lei a portas fechadas, sabotando a incipiente iniciativa de gestão social do Poder Legislativo gaúcho. O projeto foi instituído mediante decreto do governador Germano Rigotto, do Partido do Movimento Democrático Brasileiro (PMDB), ao final de seu mandato e acabou mudando "algumas coisas da Lei" que os ilhéus vinham debatendo. "De repente assumiram o projeto como deles, colocaram em votação na Assembleia" (Palmeira). Como não era mais o "governo popular" que estava, os ilhéus tiveram de "ir atrás dessas reuniões, pressionar, ir pra rua, pra algo [a APA] que quem aproveita em um primeiro momento são os ricos" (Rosa). Há relatos sobre o caso de um dono de mansão com marina que estava na área do parque e que, em uma articulação com um deputado, teve sua casa retirada desse local. Houve movimentação também dos ambientalistas que queriam uma área maior de parque. "Quem tinha seus contatos fez pressão" (Rosa).

Com o passar do tempo, as lideranças dos ilhéus perceberam que somente a lei não bastava ${ }^{7}$. Começaram, então, a pressionar o governo do estado e lançar mão de uma ampla rede de relações para que fossem implantados os conselhos, deliberativo da APA e consultivo do parque; e para que fosse elaborado um plano de manejo, com a consequente regularização fundiária.

\section{Sempre tivemos deputados interessados, desde 2001. Volta e meia surgem movimentos que dão apoio. Na prefeitura surgem funcionários interessados, mas depois saem [...]. Mas tu tens que tá em cima. Acompanhar como é que tá aquilo. Porque a nossa equipe central aqui das ilhas ainda hoje em dia está pressionando para que saia esse bendito Plano de Manejo (Irmão Gerânio).}

Esse e outros relatos dão conta do caráter organizacional da gestão social do território. É a organização territorial por eles construída que mobiliza as ações e as pressões para a resolução dos conflitos, ou seja, que luta pelo interesse público. Esse foi o caso da luta pela inclusão de representantes das organizações locais das ilhas da Pintada, das Flores, Grande dos Marinheiros e do Pavão, nos conselhos das unidades de conservação, o que originalmente não estava previsto. Entretanto, a gestão social realizada por essa organização do território nem sempre busca a construção de alternativas. Em alguns casos, ela é responsável pela resistência às ações do poder constituído.

Em 2005, após permanecer na prefeitura por 16 anos, o PT foi derrotado e uma nova coalizão de forças assumiu, tendo como prefeito José Fogaça, do Partido Popular Socialista (PPS)/PMDB. É criado um novo programa para gestão e desenvolvimento local chamado de Programa de Governança Solidária Local (PGSL). A organização do PGSL no território ocorreu sob a forma de uma Rede de Articulação composta por diferentes atores. Contudo, a implantação do PGSL nas ilhas sofreu forte resistência da organização dos ilhéus por considerar que já havia ali uma rede de articulação funcionando (a RIPCA), não havendo a

\footnotetext{
${ }^{7}$ Em 2005, quando editada a lei que criou a APA, o parque já estava instituído com o nome das entidades que ocupariam o Conselho Deliberativo da APA. Só em 2008 a gerência do parque começaria a se mobilizar para efetivamente construir o Plano de Ações Emergenciais. Em 2009 , o conselho entrou em funcionamento e ajudou a elaborar o Plano de Ações Emergenciais, que foi publicado em 3 de fevereiro de 2010, pela Portaria Sema n. 007/2010. A gerente do PEDJ explicou que ele tramitou durante um ano, tendo sido "analisado muitas vezes" e "readequado muitas vezes".
} 
necessidade de criação de um novo espaço. A prefeitura, no entanto, tinha outros planos em mente e estes incluíam a separação funcional entre os espaços: enquanto o OP seria o espaço da disputa pelo orçamento, e a RIPCA o espaço da criança e do adolescente, a Rede de Articulação do PGSL seria o espaço da "concertação". Nesse ínterim, ocorreu um embate entre as lideranças comunitárias mais participativas, identificadas com o "poder deposto", e os agentes da prefeitura ligados ao PGSL (KESSLER, 2008). "A prefeitura boicotava tudo, mas nós resistimos com amor" (Rosa).

Sem o respaldo da comunidade, a "governança" acabou ocorrendo no espaço fechado do Centro Administrativo Regional (CAR), entre seu coordenador e os membros das secretarias. Essa gestão ficou ainda mais centralizada devido às características do coordenador do CAR. Durante a gestão de José Fogaça, o cargo foi ocupado por um morador das ilhas - que denominamos, aqui, "Coronel". Além de pouco participar dos espaços públicos, ele ainda tentava impedir a participação dos demais usando diversas manobras de desmobilização e práticas clientelistas que foram denunciadas no Fórum Regional do Orçamento Participativo (FROP), gerando represálias formais e informais a membros locais do OP.

Em vários momentos, falou-se sobre a necessidade de "estar" nos espaços, justamente para que não ocorressem tais "manobras". Apesar de todos os problemas, as lideranças dos ilhéus ainda continuaram acreditando na proposta do OP, não apenas como um instrumento de definição de prioridades orçamentárias, mas como uma "ferramenta" que a população tem à disposição para fazer "com que os governos prestem conta" (Rosa). Por isso "é necessário trabalhar o coletivo, tá conversando, tá explicando, tá dizendo, que é pras pessoas poderem lutar" (Rosa).

Em 2007, após várias manifestações, o território das ilhas é finalmente reconhecido como uma região do OP, separada do Humaitá/Navegantes. Foi uma "decisão coletiva" (Rosa) dos ilhéus, manifestando o caráter organizacional dessa luta. Com isso, não só garantiam "uma fatia do bolo tributário que entra no $O P$ ", mas também faziam com que o poder público "se voltasse mais" (Rosa) para as ilhas. "Quando tu és uma região, tu acaba puxando mais o poder público pra dentro [...]. Tu lida com todas as instâncias, com todas as secretarias, então tu acaba puxando pra lá" (Rosa).

Mesmo que a conquista das ilhas, como uma região independente, tenha ocorrido em um momento de esvaziamento do OP no âmbito municipal, a comunidade das ilhas continuou insistindo na ocupação desse espaço. Esse resultado é verificado no crescente aumento da participação nas assembleias até 2010 (ver Gráfico 1). A partir desse ano, houve um desgaste em razão das estratégias de desmobilização do "Coronel" que, apesar das denúncias das lideranças, mantinha seu prestígio junto a políticos na prefeitura.

Gráfico 1

Participação nas assembleias do orçamento participativo na Região Ilhas (2007-2013)

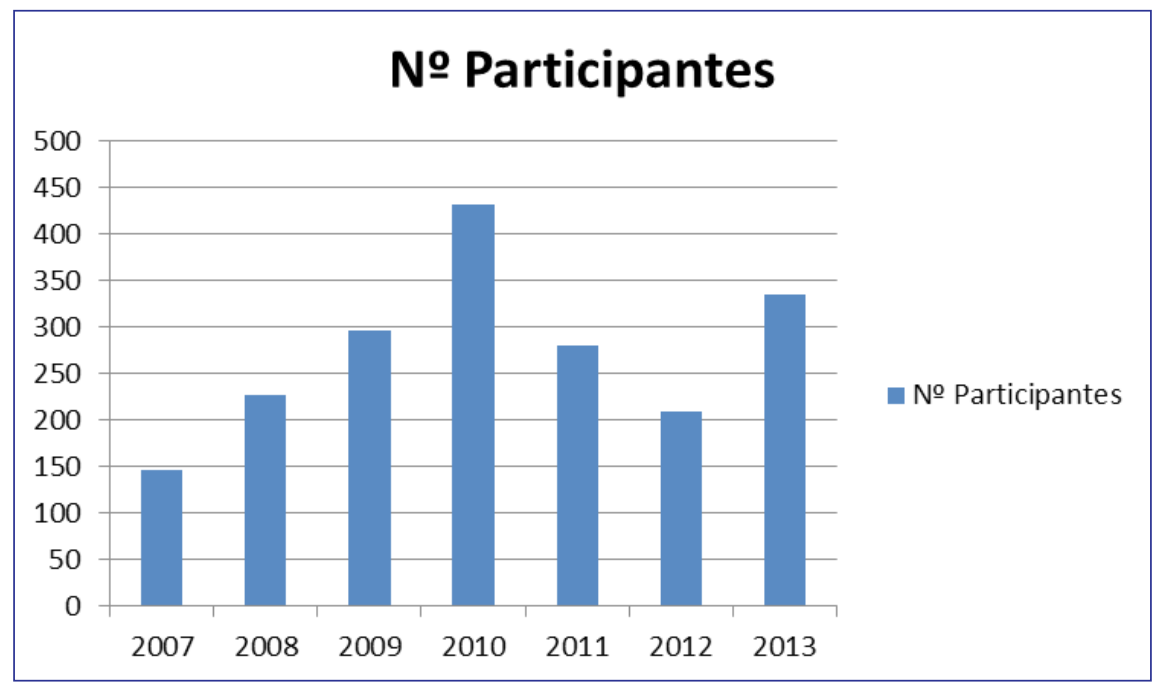

Fonte: Adaptado de Prefeitura Municipal de Porto Alegre (2014). 
Apesar do esvaziamento do FROP, visível no Gráfico 1, os ilhéus mobilizaram-se para a criação de um novo espaço de articulação. Isso ocorreu quando o então vice-prefeito José Fortunati, do PDT, assumiu a prefeitura, no lugar de José Fogaça (PMDB), que se afastou para concorrer ao governo do estado em 2010. O prefeito buscou restabelecer o diálogo com a comunidade por meio do Secretário-Adjunto de Governança local, um cargo novo em que foi colocado como titular um vereador do PDT. Esse vereador, nos últimos tempos, vinha mostrando-se interessado pelos problemas dos ilhéus, uma vez que conhecia aquela realidade como morador e participante do OP pela região Humaitá/Navegantes (conforme depoimentos das lideranças dos ilhéus). Criou-se, assim, uma rede de relações, entre os ilhéus e o Secretário-Adjunto, que eliminava as vias convencionais. Com isso, o "Coronel" passou a ser ignorado. Fato significativo foi marcar uma reunião para a discussão dos problemas locais envolvendo a Governança e as lideranças de todas as ilhas, conselheiros e delegados do OP no CTG da Ilha da Pintada, e não na sede do Centro Administrativo Regional, localizado a poucos metros de distância dali. Percebeu-se, aí, um novo espaço, algo que "não é $F R O P$, não é rede e não é o fórum" (Rosa). Seria algo semelhante à pretendida Rede de Articulação da prefeitura, porém, engendrada pelos moradores das ilhas e "se movendo sem o CAR" (Rosa).

Não se pode confundir, no entanto, essas redes de gestão social com as redes privadas de reivindicação e troca de favores que dão apoio a aliados e legitimidade a políticos. As redes privadas surgem por meio de lideranças que conseguem transitar nos gabinetes e secretarias e ganham recursos para suas organizações particulares, como foi o caso das redes de favores do "Coronel" e das peregrinações de Maricá (Cooperativa da llha Grande) aos gabinetes de vereadores, ou mesmo de Margarida, que se afastou da RIPCA porque não aceitava as sugestões propostas de intervenção em seu Clube de Mães, no momento em que perdera um importante convênio com a prefeitura devido a irregularidades em sua gestão. Essas lideranças acabaram isolando-se em suas organizações formais e perdendo o apoio da comunidade.

Em 2013, no entanto, o "Coronel" acaba "caindo", por conta da divulgação de notícias sobre o desvio de doações para as ilhas (algo há muito denunciado pelas lideranças). A nova gestão no CAR apresenta-se mais aberta ao diálogo e incorpora em sua estrutura lideranças como Junco (ligado ao PDT e aos pescadores). Percebe-se uma valorização do FROP e de espaços como a RIPCA, com a presença da gestora do CAR em suas reuniões, o que explicaria a variação positiva da participação nas Assembleias do OP em 2013, vista no Gráfico 1.

Foi possível também acompanhar o esforço das lideranças para garantir que as ilhas estivessem representadas em outros espaços, como o do Fórum de Planejamento da Região 2 (FPLAN2), que trata das questões relativas ao Plano Diretor do município. Contudo, apesar da mobilização e inclusão de vários representantes, quem acabava participando do Fórum eram "os mesmos de sempre" (Rosa). Outra situação verificada e que se relaciona com o esforço organizacional para a gestão social do território foi a do Conselho Deliberativo da APA. No final de 2010, as reuniões do conselho começaram a enfrentar problemas de quórum. Quem estava faltando às reuniões eram os representantes das associações dos "ricos", em uma espécie de estratégia de esvaziamento para impedir que o espaço operasse de acordo com interesses contrários aos seus. "Eles acharam que nós íamos cansar, mas quem cansou foram eles" (Rosa). Nesse momento, se a comunidade não estivesse participando, o Conselho da APA estaria inoperante. "Para ti eu posso dizer: é esse pequeno grupo de lideranças que fomenta e que mobiliza" (Rosa).

Notou-se na análise que lideranças de organizações do território, como a Cooperativa da llha Grande e as associações dos carroceiros, por estar preocupadas com suas lutas particulares, não participavam dos espaços. Isso acabava exigindo um esforço maior das lideranças, como ocorreu com Cravo. Apesar de não pertencer à Cooperativa da llha Grande, ele acabou assumindo essa função de representante no Conselho da APA. Isso demonstrou que não adianta existir o espaço, é preciso que a comunidade aproprie-se desse espaço, o que pode não ser tarefa fácil, uma vez que, na maioria dos casos, exige-se a atuação do representante em organizações formais.

\section{REDISCUTINDO O CAMPO E O OBJETO EMPÍRICO DA GESTÃO SOCIAL: O TERRITÓRIO E SUA ORGANIZAÇÃO}

A pesquisa recente sobre participação e gestão social tem adotado a perspectiva dos espaços formais em sua análise. Contudo, a fragmentação dos espaços deliberativos, inerente à democracia formal brasileira, torna problemática a análise da totalidade dos processos de gestão social, uma vez que restringe o social a espaços que, em muitas situações, não respeitam a lógica 
territorial e, muito menos, favorecem sua manifestação. Entretanto, no caso analisado, percebeu-se que a organização dos ilhéus promoveu uma apropriação dos espaços pelo território, permitindo seu uso para a discussão de diversos temas e com as mais diversas finalidades, desde a reivindicação até a construção de alternativas. Esse processo organizacional revela a síntese entre a administração e a política (PAULA, 2005) que ocorre na gestão social do território. Sua construção pode ser observada no Gráfico 2.

\section{Gráfico 2}

Relação entre lideranças, organizações, espaços e lutas ao longo do tempo nas ilhas

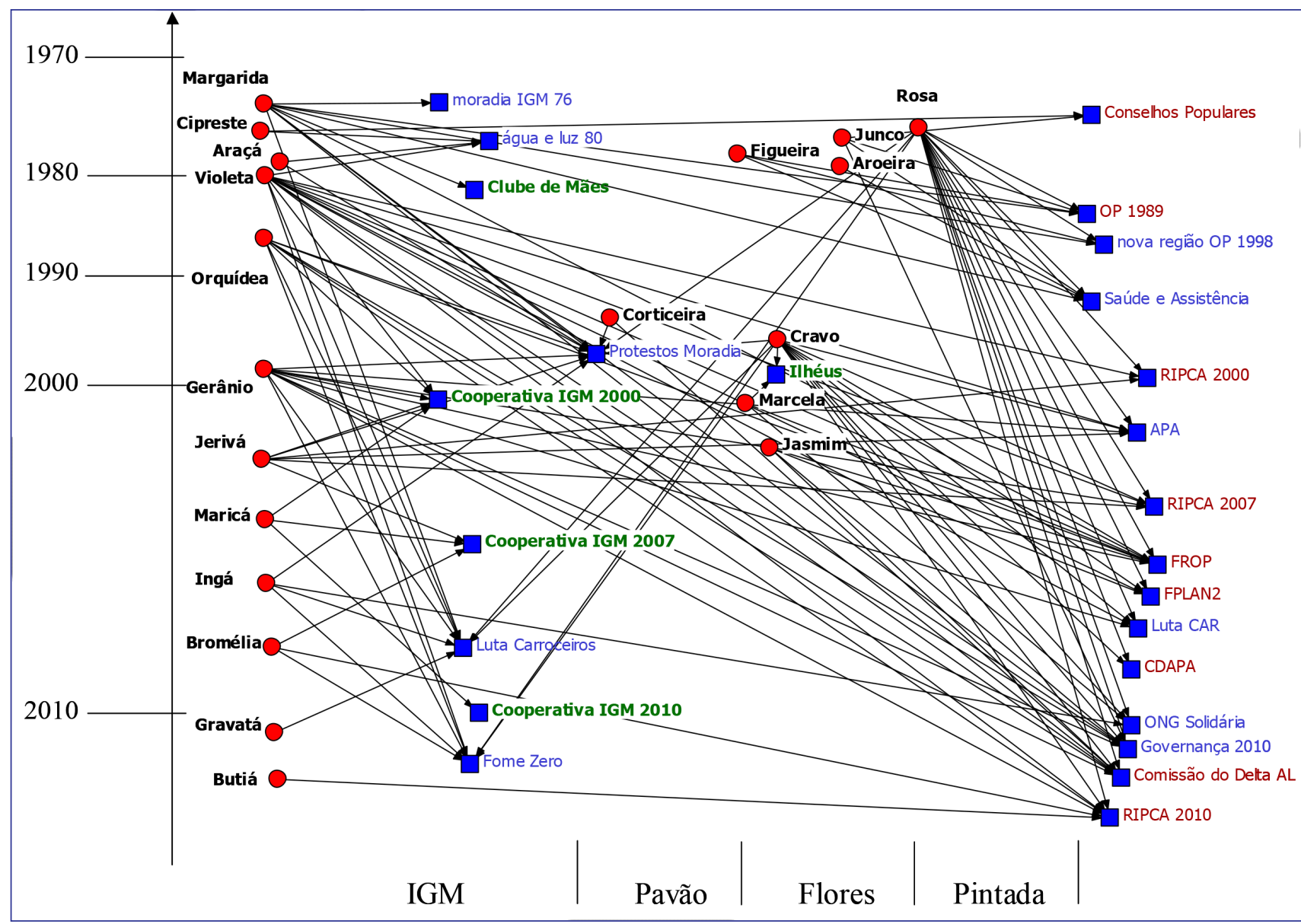

Fonte: elaborado pelos autores a partir do software UCINET (BORGATTI; EVERETT; FREEMAN, 2002; BORGATTI, 2002).

Como o próprio título mostra, o Gráfico 2 traz uma análise das relações entre as lideranças e as respectivas organizações, espaços e lutas do Arquipélago. Ao que seria uma simples visão posicional e estática de uma rede foi acrescentada dinamicidade por meio da adição das dimensões tempo e espaço. No eixo vertical localiza-se o período e no horizontal o local onde ocorre a ação, ou situa-se a organização e a liderança envolvida. As lutas (eventos) podem ser identificadas pela cor azul, e os espaços são identificados pela cor vermelha. Já as organizações são representadas pela cor verde. Note-se que foram trazidas apenas três organizações (já que a Cooperativa é apresentada em três momentos), com o objetivo apenas de ilustrar os processos que ocorrem no Arquipélago. 
A pesquisa revelou a existência de um grande número de organizações "sociais" (as $\mathrm{OS}^{8}$ no sentido funcional da lei) presentes no território. Apesar de essas organizações, em geral, terem começado com um número significativo de pessoas, com o passar do tempo, ficaram restritas a poucos participantes. O caso da Cooperativa da Ilha Grande narrado acima é emblemático. Visualiza-se pelo Gráfico o processo de esvaziamento e centralização em torno de uma liderança (Maricá). A cooperativa acabou encerrando suas atividades em 2013. O mesmo ocorreu com o Clube de Mães, apresentando-se como uma organização centrada em uma única pessoa. Percebe-se que as lideranças que se voltam para sua organização, em geral, não participam dos fóruns; uns dizem que não são convidados, outros que não têm tempo. Entretanto, o que ocorre é que aquele espaço não os interessa, pois não se vislumbra um resultado imediato na participação.

Por outro lado, tem-se o caso dos carroceiros na Ilha Grande (visível a partir das relações de Gravatá e Ingá) que, embora lutando por uma mesma causa, acabam caindo na armadilha do próprio campo e ficando presos ao jogo (illusio) político (BOURDIEU, 2007). Ocorre, então, a luta pelo poder ou por uma categoria particular apenas, sem participar de outras lutas. Assim, as diferentes lógicas dos campos sociais implicam diferentes jogos que podem atravessar os espaços públicos, transformando-os de locais de construção de consenso e solidariedade em campos de conflito (CARRION, 2009).

Contudo, ao analisar as demais lutas, percebe-se algo um tanto diverso. Elas começam isoladas (como se observa no início dos anos 1970) e, à medida que surgem novas lideranças, essas vão agregando-se ao processo e formando uma organização social. A organização social inicialmente tem um caráter particular, voltado para o interior de cada ilha. Com o passar do tempo, e conforme a participação ultrapassa o âmbito das associações locais em direção a espaços deliberativos institucionalizados (como é o caso do FROP e da RIPCA), a luta ganha contornos mais abrangentes que apontam para o território como um todo.

As lutas coletivas ou que abrangem todas as ilhas, podem ser vistas nos eventos identificados pela cor azul, no extremo direito do gráfico. Isso reforça o argumento de que a participação nos espaços favorece a percepção dos problemas como comuns a todos, ou seja, uma "compreensão" intersubjetiva da luta a partir de "significados idênticos e do reconhecimento de pretensões universais" (HABERMAS, 2002, p. 100). Nesse sentido, pode-se concordar com Habermas (2002), afirmando que a participação em espaços de palavra contribuiu para a construção da esfera pública, mas é preciso ir além, uma vez que essa construção diz respeito à solidarização em torno de uma organização, cujos membros já possuíam disposições para sua realização e para a qual contribuíram sobremaneira os conflitos por eles vivenciados (ver BAUER, 2014).

Existe muita discussão acerca do potencial que os conflitos por reconhecimento social têm para originar movimentos organizações associativas (HONNETH, 2003). E também sobre o fato de tais organizações serem uma das principais molas da ação coletiva e da participação nos espaços públicos e implementação de políticas públicas (KAUCHAKJE, 2008; LAVILLE, 2006). Essas experiências associativas e contestatórias, anteriores ou atuais, serão as responsáveis pela resistência às tentativas de limitação da participação por forças conservadoras que, de outro modo, poderiam levar ao esvaziamento do espaço (ALMEIDA, 2010; KAUCHAKJE, 2008). Tem-se, aí, alguns indícios das condições anteriores à interação comunicativa (LORD, 2007) capazes de gerar a esfera pública.

A organização social de um território representa, portanto, uma rede de relações sociais de natureza igualitária que empresta um sentido "público" às ações de uma comunidade, infiltrando-se "por todo lado nos interstícios dos sistemas 'oficiais' secundários e formalmente racionalizados do mercado e do Estado" (GODBOUT, 1992, p. 237), fazendo com que governos e organizações públicas reconheçam suas demandas e modifiquem suas práticas. A interação nos espaços públicos pode fortalecer essas redes, propiciando a formação de novas redes entre os líderes da comunidade, funcionários do governo e cidadãos, ajudando a superar o "sentimento de isolamento" e a fragmentação associada às organizações da sociedade (WAMPLER, 2010). Esse processo é visível no caso das ilhas quando, a partir da participação em espaços deliberativos como o OP e a RIPCA, as lideranças reconhecem problemas comuns e começam a articular uma luta coletiva. Nesse instante, já não são mais participantes isolados, constituíram-se em sujeito social, cuja análise seria muito difícil caso se adotasse a perspectiva de uma instância formal apenas.

Com a perspectiva de território, desloca-se o foco da participação individual em espaços formais, para o envolvimento de "sujeitos sociais" (GOHN, 2011, p. 21) em "formas de articulação interorganizacionais", ligando o associativismo local às "mobilizações na esfera pública" (SCHERER-WARREN, 2006, p. 2) em suas múltiplas formas de "ação direta" - paralisações cívicas, passeatas, ocupações, caminhadas, entre outras - (PEREIRA, 2007, p. 433) que ocorrem "por fora" da institucionalidade (SILVA, 2003, p. 30). Tem-se, aí, um processo de recriação de espaços públicos a partir do cotidiano que conecta as experiências

\footnotetext{
${ }^{8}$ A despeito da tradição sociológica do uso do termo, a denominação "Organizações Sociais" (OS) foi usurpada pelo então ministro Bresser-Pereira, no contexto da "Reforma do Estado" ao final dos anos 1990, para designar um conjunto de organizações (associações, ONG) públicas, porém, não estatais, destinadas a desenvolver atividades de interesse público em uma "estratégia" de transição de atividades estatais para o chamado "terceiro setor" (BRASIL, 1997, p. 13).
} 
dos ilhéus com as verificadas em contextos de resistência das décadas de 1970 e 1980 (GOHN, 2011; SILVA, 2003). Daquele período, pode-se igualmente resgatar uma definição importante de organização social que é bastante apropriada a esta análise. Ela, a organização, não deve ser entendida como estrutura formal e legal, mas como "articulação consciente, permanente, dinâmica, dos grupos de uma população ao redor de interesses comuns, objetivos reais, percebidos coletivamente, que alimentam ações coordenadas e que buscam satisfazer a esses interesses coletivos" (PINTO, 1980 apud SOUZA, 2010, p. 93).

Por fim, é preciso dizer que a organização territorial dos ilhéus é restrita a poucas lideranças, notadamente aquelas mais envolvidas com as lutas e espaços de decisão do território (Rosa, Cravo, Irmão Gerânio, Violeta), conforme o Gráfico 2. Isso exige um esforço muito grande daqueles que participam dessa organização. Há também uma espécie de controle social entre os participantes, para que aqueles que queiram fazer parte da organização, só tenham interesse pela "comunidade" e não em "sigla" "partido", "cargo ou voto". Isso não impede que sejam filiados a partidos políticos, mas que as ações devem ter um sentido público, orientado para "a gestão social do território" referido como "a comunidade das ilhas" (BAUER, 2014).

\section{CONSIDERAÇÕES FINAIS}

Este trabalho analisou a complexa relação entre os conflitos vivenciados pelos moradores das ilhas de Porto Alegre e o surgimento de uma organização social que busca dar conta dos processos de gestão social do território. Parte-se inicialmente da discussão a respeito da gestão social (GS), como possibilidade de uma gestão pública não estatal, que une dialeticamente administração e política, e cujo centro das análises repousa sobre a participação na esfera pública. Ocorre que, muitas vezes, essa esfera acaba reduzida aos espaços públicos instituídos, perdendo-se de vista a ampla dimensão do conflito e da capacidade dos sujeitos, que vivem e estabelecem relações em um determinado território, de transcender os espaços formais em direção a esforços organizados para a gestão social. O estudo empírico conduzido nas ilhas de Porto Alegre procurou resgatar essa dimensão.

A pesquisa apontou a existência de uma diversidade de espaços deliberativos, o que indica o potencial para o exercício da gestão social. Entretanto, os ilhéus perceberam que participar desses espaços não ocorre sem "luta". Pode-se dizer que a primeira luta acontece justamente para garantir o espaço. Em seguida, a luta é para ocupar o espaço e, por fim, para transformá-lo em uma esfera, de fato, pública, evitando seu esvaziamento e desvirtuamento. Essa luta não é individual, mas coletiva, a partir de uma organização própria do território. Reconhecê-la implica observar em detalhe a dinâmica nesses espaços e a história da constituição do território e dos sujeitos que ali vivem.

O espaço é onde ocorre a organização, onde ocorrem as relações. Ele pode ser um fórum ou conselho, mas também um espaço comum de convivência. Foi justamente nesse espaço comum que ocorreram as lutas iniciais dos ilhéus. Ora pleiteando água e luz, ora lutando contra a proibição da criação de porcos; os ilhéus mobilizaram-se por meio de protestos, interrupções de rodovia e abaixo-assinados. Todavia, o que se vê não é uma simples resistência ao poder constituído, mas uma tentativa de construir propostas em que as ações de protesto e manifestação não são dissociadas da participação em instâncias formais.

Em síntese, mais que discutir um conceito abstrato, este artigo revelou a tentativa concreta do exercício da gestão social por parte de uma organização social do território que nasce em meio a uma série de conflitos e, por que não dizer, em razão deles. Tal organização territorial, diz respeito às ações que a comunidade desenvolve para alcançar diversos fins (redistribuição, reconhecimento, respeito e autonomia) e que não se restringem à participação em espaços formais, como conselhos e instâncias de representação; muito menos é a simples articulação em rede de atores formalmente constituídos ou movimentos sociais institucionalizados. E mais, ela vai além para incluir os recursos informais, como as manifestações, os protestos, as ações simbólicas, os contatos políticos. Na verdade, não se limita à participação concedida, mas representa também aquela conquistada e que muitas vezes supera a fragmentação dos espaços públicos formais para representar algo em movimento, porém estabelecido sobre a base de um território. É, portanto, uma "gestão social do território" que se faz nos espaços, entre eles e por meio deles.

Espera-se que este trabalho contribua para o avanço nos campos da gestão pública e social ao evidenciar as relações e sobreposições entre espaços institucionalizados de participação social e a organização social, que é fruto da convivência cotidiana e das lutas que aproximam pessoas em torno de objetivos comuns. 


\section{REFERÊNCIAS}

ALMEIDA, D. R. Metamorfose da representação política: lições práticas dos conselhos municipais de saúde no Brasil. In: AVRITZER, L. (Org.) A dinâmica da participação local no Brasil. São Paulo: Cortez, 2010. 129-171 p.

AVRITZER, L. Teoria democrática, esfera pública e participação local. Sociologias, v. 1, n. 2, p. 18-43, 1999.

AVRITZER, L. Instituições participativas e desenho institucional: algumas considerações sobre a variação da participação no Brasil democrático. Opinião Pública, v. 14, n. 1, p. 43-64, 2008.

AVRITZER, L. Sociedade civil e participação no Brasil democrático, In: AVRITZER, L. (Org.). Experiências nacionais de participação social. São Paulo: Cortez, 2009. 27-54 p.

AVRITZER, L.; COSTA, S. Teoria crítica, democracia e esfera pública: concepções e usos na América latina. Dados - Revista de Ciências Sociais, v. 47, n. 4, p. 703-728, 2004.

BAIERLE, S. G. Lutas urbanas em Porto Alegre: entre a revolução política e o transformismo. Porto Alegre: Cidade - Centro de Assessoria e Estudos Urbanos, 2007.

BAUER, M. A. L. Mediações para a Solidariedade: Um estudo nas Ilhas de Porto Alegre. Cadernos Gestão Social, v. 5, n. 1, p. 131-148, 2014.

BORGATTI, S. P. NetDraw: Graph Visualization Software. Harvard: Analytic, 2002.

BORGATTI, S. P.; EVERETT, M. G; FREEMAN, L. C. Ucinet for Windows: software for social network analysis. Harvard, MA: Analytic Technologies, 2002.

BOURDIEU, P. O poder simbólico. Rio de Janeiro: Bertrand Brasil, 1989.

BOURDIEU, P. Razões práticas: sobre a teoria da ação. 8. ed. Campinas, SP: Papirus, 2007

BRANCO FILHO, C. C.; BASSO, L. A. Ocupação irregular e degradação ambiental no Parque Estadual do Delta do Jacuí - RS. Geografia, v. 30, n. 2, p. 285-302, 2005

BRASIL. Ministério da Administração Federal e Reforma do Estado / Secretaria da Reforma do Estado. Organizações sociais. Secretaria da Reforma do Estado. Brasília: Ministério da Administração e Reforma do Estado, 1997. (Cadernos MARE da reforma do estado; v. 2).

CANÇADO, A. C.; TENÓRIO, F. G.; PEREIRA, J. R. Gestão social: reflexões teóricas e conceituais. Cad. EBAPE.BR, v. 9, n. 3, p. 697-703, 2011.

CARRION, R. M. Competição e conflito em redes de economia solidária: análise do projeto de implantação da Central de Comercialização de Resíduos Sólidos de Porto Alegre (Brasil). Cad. EBAPE.BR, v. 7, n. 4, p. 547-557, 2009.

COMIN, F. et al. Pobreza: da insuficiência de renda à privação de capacitações. Uma aplicação para a cidade de Porto Alegre através de um indicador multidimensional. Porto Alegre: UFRGS, 2006. Mimeografado.

CUNHA, F. S. Movimentos sociais urbanos e a redemocratização: a experiência do movimento favelado de Belo Horizonte. Novos Estudos CEBRAP, n. 35, p. 133-143, 1993.
DAGNINO, E. Os movimentos sociais e a emergência de uma nova noção de cidadania. In: DAGNINO, E. (Org.). Anos 90: política e sociedade no Brasil. Rio de Janeiro: Brasiliense, 1994. 103-115 p.

DAGNINO, E.; OLIVEIRA, A. J.; PANFICHI, A. (Org.). A disputa pela construção democrática na América Latina. São Paulo/Campinas: Paz e Terra/Unicamp, 2006.

DAGNINO, E.; TATAGIBA, L. (Org.). Democracia, sociedade civil e participação. Chapecó, SC: Argos, 2007.

FLORES, D. Aproveitamento de resíduos orgânicos na agricultura urbana. (Orientações para a Formulação de Políticas Municipais para a Agricultura Urbana, n. 5), 2003. Disponível em: <http://agriculturaurbana.org.br/sitio/textos/AU05icdr.pdf>. Acesso em: 19 jul. 2015.

GODBOUT, J. O espírito da dádiva. Lisboa: Instituto Piaget, 1992.

GOHN, M. G. Novas teorias dos movimentos sociais. São Paulo: Loyola, 2008.

GOHN, M. G. Conselhos gestores e participação sociopolítica. 4. ed. São Paulo: Cortez, 2011.

GOMES, J. J.; MACHADO, H. V. S.; VENTIMINGLIA, M. A. Arquipélago: as ilhas de Porto Alegre. In: PORTO ALEGRE (Município). Memória dos bairros. Porto Alegre: Secretaria Municipal de Cultura, 1995. 6-132 p.

HABERMAS, J. Acções, actos de fala, interacções linguisticamente mediadas e o mundo vivo (1988). In: HABERMAS, J. Racionalidade e comunicação. Lisboa: Ed. 70, 2002. 103-147 p.

HABERMAS, J. Direito e democracia: entre a facticidade e a validade. Rio de Janeiro: Tempo Brasileiro, 2011. v. 2.

HONNETH, A. The critique of power: reflective stages in a critical social theory. Cambridge, MA: The MIT Press, 1991.

HONNETH, A. Luta por reconhecimento: a gramática moral dos conflitos sociais. São Paulo: Ed. 34, 2003.

KAUCHAKJE, S. Solidariedade política e constituição de sujeitos: a atualidade dos movimentos sociais. Sociedade e Estado, v. 23, n. 3, p. 667-696, 2008.

KESSLER, C. K. Politizando o conceito de redes de economia solidária: uma análise à luz da teoria dos campos de Pierre Bourdieu. Dissertação (Mestrado em Administração) - Programa de PósGraduação em Administração, Universidade Federal do Rio Grande do Sul, Porto Alegre, 2008.

LAVILLE, J.-L. Ação pública e economia: um quadro de análise. In: FRANÇA FILHO, G. C. et al. Ação pública e economia solidária: uma perspectiva internacional. Porto Alegre: Ed. UFRGS, 2006. 21-37 p.

LORD, L. Distinções entre a esfera pública habermasiana e os espaços públicos brasileiros. In: DAGNINO, E.; TATAGIBA, L. (Orgs.). Democracia, sociedade civil e participação. Chapecó, SC: Argos, 2007. 453-473 p.

MESQUITA, Z. Do território à consciência territorial. In: MESQUITA, Z.; BRANDÃO, C. R. (Orgs.). Territórios do cotidiano. Porto Alegre/ Santa Cruz do Sul, RS: Ed. UFRGS/Ed. Unisc, 1995. 76-92 p. 
MESQUITA, Z.; BAUER, M. A. L. Com os olhos de Maria: organizações familiares e territorialidade. In: CARRIERI, A. P.; SARAIVA, L. A. S.; GRZYBOVSKI, D. (Orgs.). Organizações familiares: um mosaico brasileiro. Passo Fundo, RS: Ed. UPF, 2008. 288-325 p.

MILANI, C. R. S. O princípio da participação social na gestão de políticas públicas locais. Rev. Adm. Pública, v. 42, n. 3, p. 551-579, 2008.

MOSCARELLI, F. C. et al. Inserindo o saber local para eficácia dos planos de gestão de unidades de conservação: o caso do delta do Jacuí. In: SIMPÓSIO DE ÁREAS PROTEGIDAS, 3., 2005, Pelotas. Anais... Pelotas, RS: Universidade Católica de Pelotas, 2005. 1 CD-ROM.

NOBRE, M. Prefácio. In: HONNETH, A. Luta por reconhecimento: a gramática moral dos conflitos sociais. São Paulo: Ed. 34, 2003. 07-19 p.

OLIVEIRA, V. A. R.; CANÇADO, A. C.; PEREIRA, J. R. Gestão social e esfera pública: aproximações teórico-conceituais. Cad. EBAPE.BR, v. 8, n. 4, p. 613-626, 2010.

ORTIZ, R. Um outro território. São Paulo: Olho d'Água, 1999.

PAULA, A. P. P. Administração pública brasileira entre o gerencialismo e a gestão social. Revista de Administração de Empresas, v. 45, n. 1, p. 36-49, 2005.

PEREIRA, M. A. G. Modelos democráticos deliberativos e participativos: similitudes, diferenças, desafios. In: DAGNINO, E.; TATAGIBA, L. (Orgs.). Democracia, sociedade civil e participação. Chapecó, SC: Argos, 2007. 421-452 p.

PERISSINOTTO, R. M.; FUKS, M. Recursos, influência política e cultura cívica nos conselhos gestores de Curitiba. In: DAGNINO, E.; TATAGIBA, L. (Orgs.). Democracia, sociedade civil e participação. Chapecó, SC: Argos, 2007. 43-76 p.

PORTO ALEGRE (Município). História do bairro arquipélago. Porto Alegre: Observatório da Cidade de Porto Alegre, 2008. Disponível em <http://www2.portoalegre.rs.gov.br/observatorio/default. php?p_bairro=104\&hist=1\&p_sistema=S>. Acesso em: 28/07/2008.

PREFEITURA de Porto Alegre. Porto Alegre em Análise: Séries Históricas/ Região Ilhas (Tema: Democracia Participativa). Porto
Alegre: Observatório da Cidade de Porto Alegre, 2014. Disponível em: <http://portoalegreemanalise.procempa.com.br/?regioes=18_14_0>. Acesso em: 08/07/2014.

QUEIROZ, M. I. P. Relatos orais: do "indizível" ao "dizível". In: VON SIMSOM, O. M. (Org.). Experimentos com histórias de vida (ItáliaBrasil). São Paulo: Vértice/Revista dos Tribunais, 1988. 14-43 p.

SCHERER-WARREN, I. Das mobilizações às redes de movimentos sociais. Sociedade e Estado, v. 21, n. 1, p. 109-130, 2006.

SILVA, I. G. Democracia e participação na reforma do Estado. São Paulo: Cortez, 2003.

SILVA, M. Z. et al. Perfil dos conselhos gestores da Prefeitura Municipal de Vitória (1984-2003). In: SILVA, M. Z.; BRITO JUNIOR, B. T. (Org.). Participação social na gestão pública: olhares sobre as experiências de Vitória-ES. São Paulo: Annablume, 2009. 17-115 p.

SOLINÍS; G. O que é o território ante o espaço? In: RIBEIRO, M. T. F.; MILANI, C. R. S. (Org.). Compreendendo a complexidade socioespacial contemporânea. Salvador: Ed. UFBA, 2009. 265-288 p.

SOUZA, M. L. Desenvolvimento de comunidade e participação. São Paulo: Cortez, 2010.

TATAGIBA, L. A participação sob o marco da "democracia gerencial". In: OLIVEIRA, A. J.; PANFICHI, A. (Org.). A disputa pela construção democrática na América Latina. São Paulo/Campinas, SP: Paz e Terra/Unicamp, 2006. 137-179 p.

WAISMAN, M. Estudo da viabilidade econômica do reaproveitamento de resíduos orgânicos via suinocultura. Dissertação (Mestrado em Administração) - Programa de Pós-Graduação em Administração, Universidade Federal do Rio Grande do Sul, Porto Alegre, 2002.

WAMPLER, B. Transformando o Estado e a sociedade civil por meio da expansão das comunidades política, associativa e de políticas públicas. In: AVRITZER, L. (Org.) A dinâmica da participação local no Brasil. São Paulo: Cortez, 2010. 394-439 p.

Márcio André Leal Bauer

Doutor em Administração; Professor Adjunto do Programa de Pós-Graduação em Administração - PPGA/FURG; Coordenador do Núcleo de Estudos em Organização, Trabalho e Participação - NOTeP/ICEAC/FURG. E-mail: mbauer@vetorial.net

Rosinha da Silva Machado Carrion

Socióloga; Pós-doutorado em Développement et Societés (IEDES/Paris I); Professora Titular do Programa de Pós-Graduação em Administração/PPGA da Universidade Federal do Rio Grande do Sul; Coordenadora do Núcleo Interdisciplinar de Pesquisa e Estudos sobre o Terceiro Setor- NIPETS/PPGA/ UFRGS. E-mail: carrion@ea.ufrgs.br 